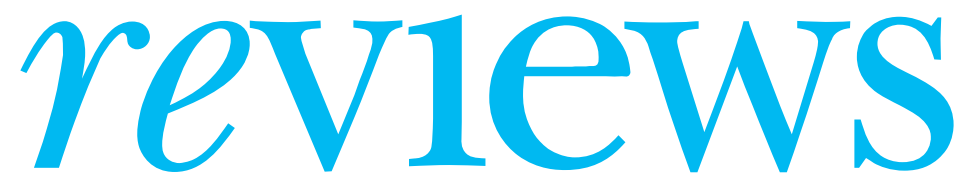

BOOKS • CD ROMS • ART •WEBSITES $\bullet$ MEDIA $\bullet$ PERSONAL VIEWS $\bullet$ SOUNDINGS

Iill

iWITNESS: A

Retrospective Photographic Exhibition by Tom Stoddart

2 More London Riverside, South

Bank, London SE1 2DB, until 18

August

www.dec.org.uk

Rating: $\star \star \star \star$

$\mathrm{A}$

mounted text at the entrance to British photojournalist Tom Stoddart's latest exhibition states, "It is sad and unnecessary that any of these photos exist." This powerful selection of Stoddart's often harrowing images-designed to mark the 40th anniversary of the Disasters Emergency Committee-is a personal view of someone who has observed the major humanitarian and health emergencies of the past decade at first hand; and is adamant that these events are not forgotten.

Stoddart, who has worked for international magazines such as Time and Newsweek, and British newspaper the Sunday Times, has captured those moments in which unutterable misery meets human courage, strength, and compassion. His pictures rarely need explanation-for example, the image of disoriented and frightened people helping each other as cholera sweeps through Kibumba camp in Goma on the Rwanda/ Zaire border in 1994. During the refugee crisis, 50000 people died here in a fortnight.

Stoddart's photographs humanise what to many in the West are merely grim statistics clocking up a long way away. They portray innocent people, trapped by circumstances beyond their control, and serve as a timely reminder of the horrors of war, and the effects of mankind's greed, intolerance, and prejudice.

Notably absent in this catalogue of disasters are images from today's biggest international humanitarian crisis-that in Darfur, western Sudan: the true horrors of which are still yet to unfold. Around one million desperate civilians are internally displaced, thousands are living in dire conditions in neighbouring Chad, while the violence and murder continue with impunity. A statement by Médecins Sans Frontières this week says that the threat of famine is looming rapidly, and thousands will likely starve if immediate action is not taken by the international community.

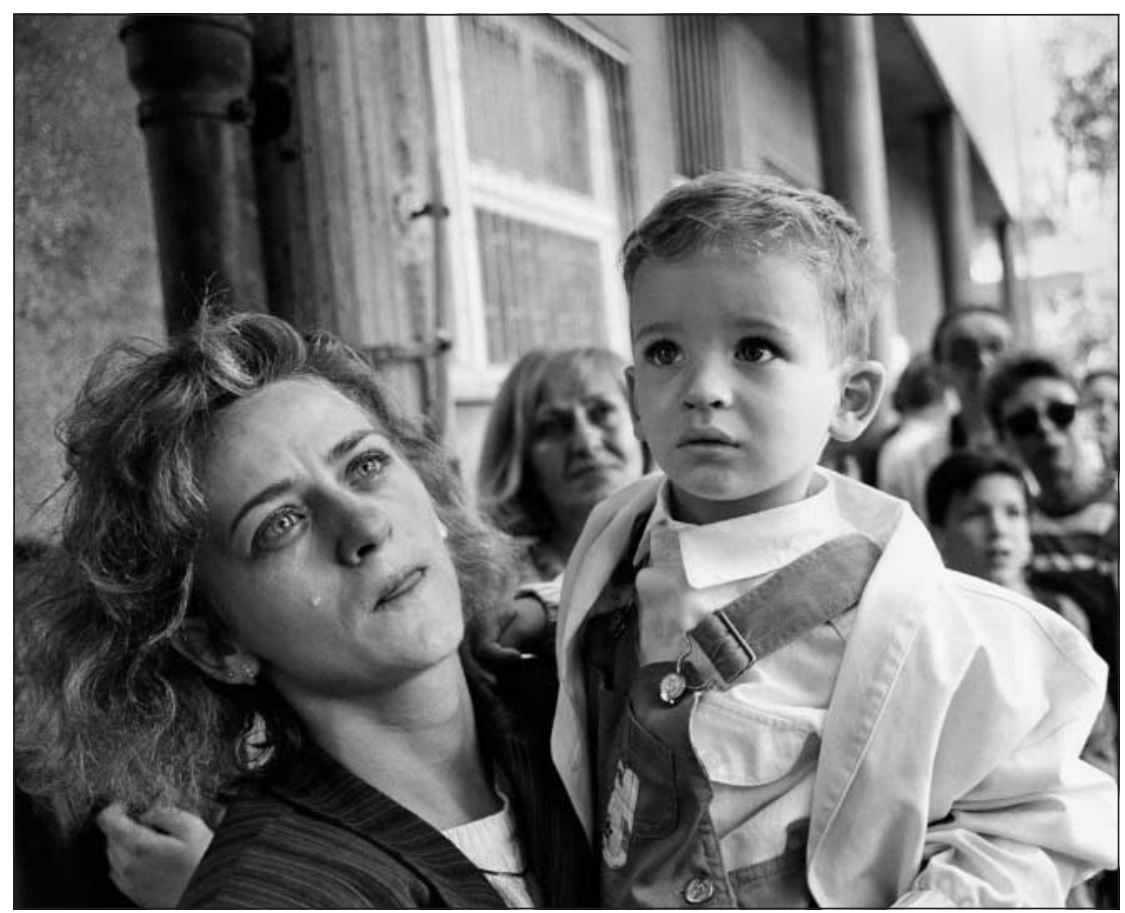

A mother prepares to evacuate her child from Sarajevo during the Bosnian war

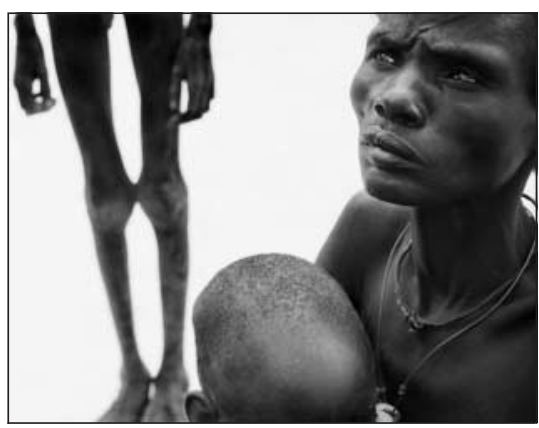

A Dinka mother waits silently for food for her starving children during the 1998 famine in southern Sudan

Seeing Stoddart's photos of the last famine in south Sudan in 1998, beautifully composed yet each telling its own miserable story, was for me a depressing reminder of the relentless cycle of suffering that the population of this beleaguered country has faced. Stoddart says he was driven to photograph the 1998 famine, in which 100000 died, because at the time the famine was being ignored by the West, and it made him angry. "I can't quite believe that we are now allowing this cycle of violence and human misery to continue today in Darfur," he told the $B M J$.

Few photojournalists have articulated such human catastrophes quite as well as Stoddart has over the years. Indeed, Stoddart sees himself more as a messenger than an artist, whose job it is to bring back images from the most desperate corners of the earth that evoke a sense of outrage in those who see them. Thus he seeks to engage the public and demand that people act. Images are certainly an effective way of doing that: they stir people's consciousness in ways that words can't. Stoddart's perseverance to ensure that forgotten emergencies are placed on the media radar, and to get the public to dig deep into their pockets to donate to the aid agencies working there, is admirable.

I asked him whether such individual donations would ultimately do anything to stop the cycle of violence in places like Sudan. Surely the crisis in Darfur needed political solutions, not individual donations from the British public? "I'm not saying that my images will change the world," Stoddart replied, "but it is a drip drip drip effect, and human images like these make a powerful contribution to ensuring that change."

Sally Hargreaves journalist, London salhargreaves@yahoo.co.uk 
Internal Bleeding: The Truth Behind America's Terrifying Epidemic of Medical Mistakes

Robert M Wachter, Kaveh G Shojania

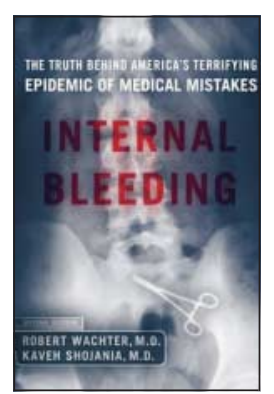

Rugged Land,

$\$ 24.95 / \$ C 36.95$, pp 320

ISBN 1590710169

www.ruggedland.com

Rating: $\star \star \star$

A

with so many before them, Wachter and Shojania, practising doctors in the United States, start their book with a prologue outlining their own involvement in patient safety issues. It seems that everyone must undergo a public catharsis before they are able to talk about safety and harm. It was thus, with this formulaic confession, that I was immediately put off this book, assuming that it would not add much to the safety literature. However, as soon as I realised that this book was not for people like mesafety junkies-or even directed at clinicians without a special interest in the field, but for patients, my interest was rekindled.

How would the authors explain this complex field to patients? Rather well in my opinion. Overall they capture the difficult issues involved, including the often conflicting dilemmas facing those working in health care; and the balance between no blame/ blame the system, and personal responsibil- ity. But having just described how this book is aimed at patients I would not like to put off others, even those supposedly knowledgeable in the field of patient safety, as the authors put their case authoritatively.

The book takes us straight into an important issue for health care, and indeed for patients-the distorting effects of looking back when there has been harm, known as hindsight bias. It then takes us into the problems this can cause, particularly where solving one safety issue leads to another. In the way in which this was explained, I could see that patients would understand these complicated issues.

Throughout, the book tackles areas where there is ambiguity and conveys the problems that clinicians face every day. I felt as if Wachter and Sojania had done clinicians a favour. I was pleased to see the authors cover the problems-surely more acute in the UK healthcare system-of the divide between hospital and community, outlining, for example, how early discharge has rarely been augmented by better communication and follow up.

If, though, the issues on safety are generally well balanced, there are sometimes problems. For instance, the authors reveal their hospital bias with their support for $\mathrm{Hal}$ Luft's research purporting to show that specialist care is better care. The factors around what is "best" are increasingly seen as more complicated than Luft's original research suggests, not least of all because patients themselves have a view on what is good care, and few patients fit into the stereotypical single disease model promulgated in the specialist versus generalist debate. Further, the book is unapologetically US focused (but then the title tells you that). That shouldn't deter non-US readers too much-just make allowances.

The BMJ has outlined the issue of communicating risk, and this book does it elegantly, explaining how risk can be confusing, how irrational perceptions can be, and generally how apparently large differences in outcome affect only a few people (for example, a $50 \%$ relative risk change might have a small effect on absolute risk). Unfortunately they fall into the trap of many in health care when later they suggest that different management of a patient with chest pain would have saved her life. If only they had stuck to their aim of not oversimplifying; the truth is that there is a small chance that different management of the patient would have altered the outcome.

Generally each chapter starts with a story, the human dimension of safety. This is effective and certainly catches the reader's attention. But after a while I found myself skipping the stories to get to the underlying issues. The stories began to irritate: they are long, described in too much detail, andwith all their added emotion-begin to read like an episode of $E R$. One could only wait for the helicopter to slice off an arm.

I wonder who the publishers think will read this book? It is long and, unless the reader has a particular interest in this field, there is a lot to get through. The stories will help some people access it more readily, but for others, like me, they will act as a barrier. However, I would like to think that my patients have read this book so they can better understand the issues facing clinicians.

Tim Wilson general practitioner and policy analyst, strategy unit, Department of Health

Tim.Wilson@doh.gsi.gov.uk

\section{Doctors' Errors and} Mistakes of Medicine: Must Health Care Deteriorate? Molshe Wolman, Ruth Manor

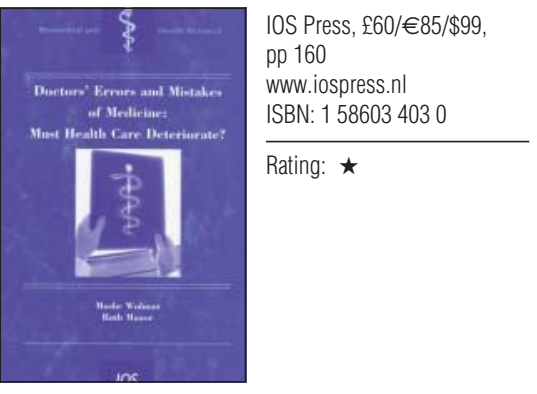

$\mathrm{M}$ edicine is immersed in an orgy of self doubt. I am reminded of a scene in Bergman's film The Seventh Seal, in which the knight and the squire watch a stream of flagellants walk and crawl past, beating themselves and each other in an attempt to avert the plague. As we beat ourselves, there are some who wish us to whip even harder and a small number who deem us incapable of redemption. There cannot be any among us who still doubt the existence of the plague.

Medicine is an uncertain activity, in which there is no substitute for learning and training on sick patients; it is inevitable that doctors will make mistakes, and some mistakes will kill people. The questions concern what sort of mistakes are permissible, how often one is allowed to make them, what the public reaction should be, and how we are to deal with them.

Moshe Wolman, a retired professor of pathology, and Ruth Manor, a professor of philosophy, are Israelis. They write very much from a United States viewpoint, perhaps because the Israeli health service is similar, and early in the book the relevance of their message to the NHS recedes. Among the main causative factors in errors and adverse events in medicine is "the steady decrease in monitoring of the quality of medical treatment." Whatever has happened to medical care in the United Kingdom, it is not from lack of monitoring. They are also wary of the motives of private medicine: "[Medicine] is not a business venture and needs not be a profit-making activity."
Although the present government seems keen to learn from the United States, such ventures have so far had little effect.

Unusually for a book about doctors' errors, there is no classification and careful definition of types of error (slips and lapses, violations, and so on), only a loose categorisation of minor and major errors. It is almost a personal memoir of diagnostic errors encountered over a lifetime's practice, and mainly a lament for the diminishing number of autopsies. The number of autopsies is a worry in the United Kingdom too, but this is not because doctors are wary of them in case they reveal mistakes that lead to media exposure and litigation-it is because of the Alder Hey affair and the other events that led to the Human Tissue Bill, but these are not mentioned.

The inflammatory and pessimistic subtitle is unnecessary. Although the authors cite several papers to support their case, they have not convinced me that health care is deteriorating.

Neville W Goodman consultant anaesthetist, Southmead Hospital, Bristol

Nev.W.Goodman@bris.ac.uk 


\section{Balancing the benefits and harms of care}

$\mathrm{C}$ an patients have too much information about the benefits and harms of treatment? Until a year ago, I wasn't sure of the answer to this. Why worry people needlessly about outcomes that are rarer than hen's teeth? And why burden junior staff with lengthy consent forms?

Having just spent the past 12 months being treated for breast cancer, I am now convinced that people need as much good quality information as they can get. Why?

Firstly, I wanted to optimise my prognosis by making good decisions. Less obviously, I wanted to be able to comfort myself post hoc that I had made the best decisions possible at the time. (It would be cold comfort were my family and I later to discover reliable research favouring different decisions than was available last year.)

Secondly, I needed to recognise the effects of treatment, both good and bad, when they occurred. For example, being aware that neutropenia below about $0.5 \times 10^{9} / 1$ carried a small but real risk of sepsis made it easier for my partner and me to get to an emergency department when it happened and to reconcile ourselves to curtailing our holiday in Scotland. By contrast, without good information, I spent about six weeks needlessly worrying about hip pain that I feared might be

I spent about six weeks needlessly worrying about hip pain metastatic, before discovering it to be a lesser known effect of one of the drugs I was taking.

Thirdly, I needed reliable treatment information in order to come to terms with the reality of my condition. Knowing the likely effects of chemotherapy and radiotherapy helped manage practical matters, such as work arrangements and family visits from Australia. In addition, being able to grasp that I really did have cancer ("Me? A 30-something doctor, and an evidence based one at that!") became something of a milestone of the disease process-one achievement, at least, from a topsy-turvy year.

Finally, good information helped me forge more open relationships with health professionals, family, and friends. For example, having reliable prognostic data helped us speak openly about the (happily small) chance of dying. This in turn made speaking about everything else easier.

So what kind of treatment information seemed "good"? Firstly, it had to be in "bite sized" pieces, repeated many times and available on the days when I found myself able to cope with it. This rarely coincided with doctors' appointments, so online information and printed brochures were good. Even better were the specialist nurses, whom I could telephone in moments of terror such as when I was convinced my headache was a brain metastasis. care.
Information also had to be psychologically appropriate. Clinical texts stated all my worst fears just a bit too baldly. Some consumer texts were written too much from the author's experience to be of much use generally, or infused with too much moralistic outrage at doctors to be of much use to me. Some, though, like the DIPEx website (www.dipex.org), provided valuable insights into people's experience with treatments, which helped flesh out statistical evidence.

On that note, above all else, I needed treatment information that was specific and properly evidence based. My job had accustomed me to having reliable evidence for most health questions. But when the crunch came I surprised even myself with my need for it. By evidence based, I mean information derived from a rigorous method of screening all available research for validity to my question. I found that positive answers were helpful (such as antioestrogen drugs are likely to work), but so too were negative ones (we don't yet know the effects of chemotherapy on cognition) as they enabled me to make honest decisions and to take into account other, more certain considerations.

I found the widespread, magical thinking that favoured an exclusive diet of crystals, celery juice, and the like to be verging on immoral. By contrast, my own NHS breast care nurse was outstanding in her ability to discuss the pros and cons of treatment in a psychologically sound way.

Perhaps my need for evidenceincluding certainty about uncertaintypartly reflected a need for something trustworthy when so much that I had taken for granted was being turned upside down. I found reliable evidence in four places, beyond which I didn't need anything else. The first three-Clinical Evidence, Best Treatments, and the Cochrane Library-are all widely available (and, no, I didn't get paid extra to write this).

The fourth evidence source was my colleague's summary of the evidence, tailored for me. His "Bottom Lines for Early Breast Cancer (Premenopausal)" saved me a lot of time and made me trust my doctors faster. It enabled me to undergo chemotherapy without too much fuss and to begin the long process of coming to terms with the possible consequences, such as fertility ablation. But then, as my oncologist helpfully pointed out, death is terrible for fertility.

\section{Anna Donald honorary fellow in epidemiology,} University College London

Competing interests: I am a director of Bazian, a company specialising in evidence based health

\section{SOUNDINGS}

\section{The good old days}

After I started in general practice I worked a one-in-two night rota for 12 years. By the end, I was thoroughly burnt out and had so little empathy left that I could sit through Spencer Tracy's death scene in Captains Courageous without blubbering. I hated being called out of bed and calling me was as pointless as Tantalus's mother shouting, "Come on, son, eat your dinner." My only remaining virtues were sarcasm and lust, my only emotions apathy and self pity, and I was ready to start slaughtering my staff-only I wasn't sure how to hide their still-quivering bodies from the fuzz.

But when the opportunity of joining an out-of-hours cooperative arose, instead of jumping on it like a health insurance company on the occasional perfectly genuine claim, my feelings were curiously equivocal. Would the patients stand for it? Would there be marching in the streets? Or would they just be quietly hurt and disappointed? He's not the same calibre as old Doc Jackson, they'd be saying-he doesn't really care, he's let us down, after our thinking so much of him and nominating him for that award, The Best Doctor In The World ... Ever. There is no joy in Mudville, mighty Casey has struck out.

In the end, despite my reservations, I joined the coop and it has proved a smart move. It saved my sanity, allowing me to spend more time with my family, drink more heavily, and join an extreme fascist organisation that considers global warming to be a good thing. I'm also now so chock-full of empathy that when I say, "Have a nice day," I sometimes actually mean it.

Yet there remains a small stubborn part of me that misses the old days, like a successful artist yearning for his lonely days in the garret eating muffins soaked in spit. My great $\sin$ is nostalgia, and time has softened the memories, so I tend to forget the unrelenting long hours, the trivial calls, the physical exhaustion, the wanting to kick somebody. Instead I miss the intimacy, the being there, the always knowing what was going on, the always feeling in control.

Unfortunately, I've found that my patients are getting along very well without me, thanks very much; any competent doctor is quite acceptable, even if he or she doesn't know their seed, breed, and generation. I guess that, most of all, I miss being needed. 